Ciência e Natura, Santa Maria, v. 37 n. 4 set-dez. 2015, p. 564-576

Revista do Centro de Ciências Naturais e Exatas - UFSM

ISSN impressa: 0100-8307 ISSN on-line: 2179-460X

\title{
ciênciaenatura
}

\section{A produção do arroz orgânico no assentamento novo horizonte II, localizado no município de Santa Margarida do Sul/RS}

The organic rice production in settlement novo horizonte II, located in the municipality of Santa Margarida do Sul / RS.

João Silvano Zanon, Leandro Jesus Macield de Menezes, Carmen Rejane Flores Wizniewsky, Helena Maria Beling

Universidade Federal de Santa Maria, Departamento de Geociências, Geografia Agrária, UFSM, RS, Brasil

\section{Resumo}

O artigo trata da produção do arroz orgânico no assentamento Novo Horizonte II, localizado no município de Santa Margarida do Sul/RS. Sendo esta uma agricultura alternativa, com base na agroecologia, tendo preocupações econômicas, sociais e ambientais. A área de estudo conta com a diversificação na produção, que garante autonomia produtiva $e$ sustentabilidade, fornecendo as condições de permanência do homem no campo. Neste assentamento são produzidos vários tipos de arroz orgânico, os assentados envolvidos com este sistema produtivo estão buscando constantemente técnicas, tecnologias, métodos e metodologias que facilitem e melhor se adaptem a esta produção, garantindo ganhos na qualidade e na quantidade produzida. Esse tipo de produção potencializa o desenvolvimento local e regional. Com o passar dos tempos é notado uma melhora na aceitação dos consumidores com os produtos orgânicos.

Palavras chave: arroz orgânico; sustentável; agroecologia; assentamento Novo Horizonte II; Santa Margarida do Sul/RS.

\begin{abstract}
The article is about the production of organic rice in the settleent Novo Horizonte II, located in the municipality of Santa Margarida do Sul / RS. This is a alternative agriculture based on agroecology, considering economic, social and environmental concerns. The study area has the diversification in production, that ensuring the autonomous production and sustainability, providing the conditions of permanence of the man in the field. In this settlement various types of organic rice are produced, the settlers involved with this production system are constantly looking for the techniques, technologies, methods and methodologies to facilitate and better suited to this production, guaranteeing earningsin quality and quantity produced. This type of production potentiate the local and regional development. With the passage of time is noticed an improvement in consumer acceptance with organic products.
\end{abstract}

Keywords: organic rice; sustainable; agroecology; settlement Novo Horizonte II; Santa Margarida do sul / RS

\section{Introdução}

Partindo do fato de que, a história agrária brasileira contribuiu para que sua estrutura fundiária fosse altamente concentrada, visto que, além da irregular distribuição de terras, as desigualdades sociais sempre permaneceram no território. Os grandes produtores, representantes do agronegócio, obtém acesso a um maior volume de financiamentos e demais políticas públicas para desenvolver a produção nas grandes 
lavouras, enquanto os agricultores familiares camponeses penam para produzir a maior parte dos alimentos consumidos pelos brasileiros.

A principal característica da estrutura fundiária do Brasil esta pautada na concentração de terras, pois os latifundiários obtêm acesso às políticas públicas para desenvolvimento de sua produção, que é voltada para o agronegócio, financiando novas tecnologias para os índices agropecuários aumentarem.

A modernização agrícola fez com que os agricultores passassem a depender do modelo baseado no capital, com sua produção dependente dos pacotes tecnológicos das grandes empresas. Este modelo trouxe consequências graves para os pequenos agricultores desprovidos de capital que, sem recurso para consumir os pacotes tecnológicos modernos e sofisticados, a exemplo dos insumos químicos e sementes geneticamente modificadas, foram expropriados do campo.

Surge então à problemática, ocorrendo uma crise do modelo agrícola convencional, devido à agricultura convencional causar danos sociais, ambientais e econômicos, surgindo assim, a necessidade de se introduzir uma agricultura alternativa, bem como o fortalecimento da agricultura familiar.

Devido às pressões dos movimentos sociais, sobretudo do Movimento dos Trabalhadores Rurais Sem Terra (MST), foram criados assentamentos de reforma agrária, que tem em sua essência, desenvolver sistemas produtivos a partir das técnicas agroecológicas, produzindo alimentos voltados para o consumo familiar e comércio de excedentes, sendo esta uma agricultura sustentável, que prioriza a busca pela qualidade de vida das atuais e futuras gerações, sendo vista com grande viabilidade social, ambiental e econômica para os pequenos agricultores familiares assentados.

A pesquisa abordou a produção do arroz na forma orgânica no assentamento Novo Horizonte II, localizado no município de Santa Margarida do Sul/RS.

Segundo dados da Embrapa (2006), a agricultura orgânica é o sistema de manejo sustentável da unidade de produção, com enfoque sistêmico, que privilegia a preservação ambiental, a agrobiodiversidade, os ciclos biogeoquímicos e a qualidade de vida humana, satisfazendo as necessidades de cada unidade de produção de forma qualitativa.

[...] a atividade humana é dominada pela exigência de satisfazer as necessidades de cada unidade de produção, que é ao mesmo tempo uma unidade de consumo. Por isso aqui o orçamento é em grande medida qualitativo: para cada necessidade familiar é necessário prover, em cada unidade econômica, o produto in natura qualitativamente correspondente. (CHAYANOV, 1981 p.136).

O município de Santa Margarida do Sul, segundo dados do Instituto Brasileiro de Geografia e Estatística (IBGE, 2010) esta localizado na porção sudoeste do estado do Rio Grande do Sul, na região da Campanha Gaúcha. Limita-se com os municípios de Lavras do Sul, Vila Nova do Sul e São Gabriel. O município tem uma população total de 2.352 habitantes, com área de 955,299 $\mathrm{Km}^{2}$, obtendo a densidade demográfica de 2,46 habitantes por $\mathrm{Km}^{2}$, conforme Figura 1. 
Figura 1: Mapa de localização de Santa Margarida do Sul /RS.

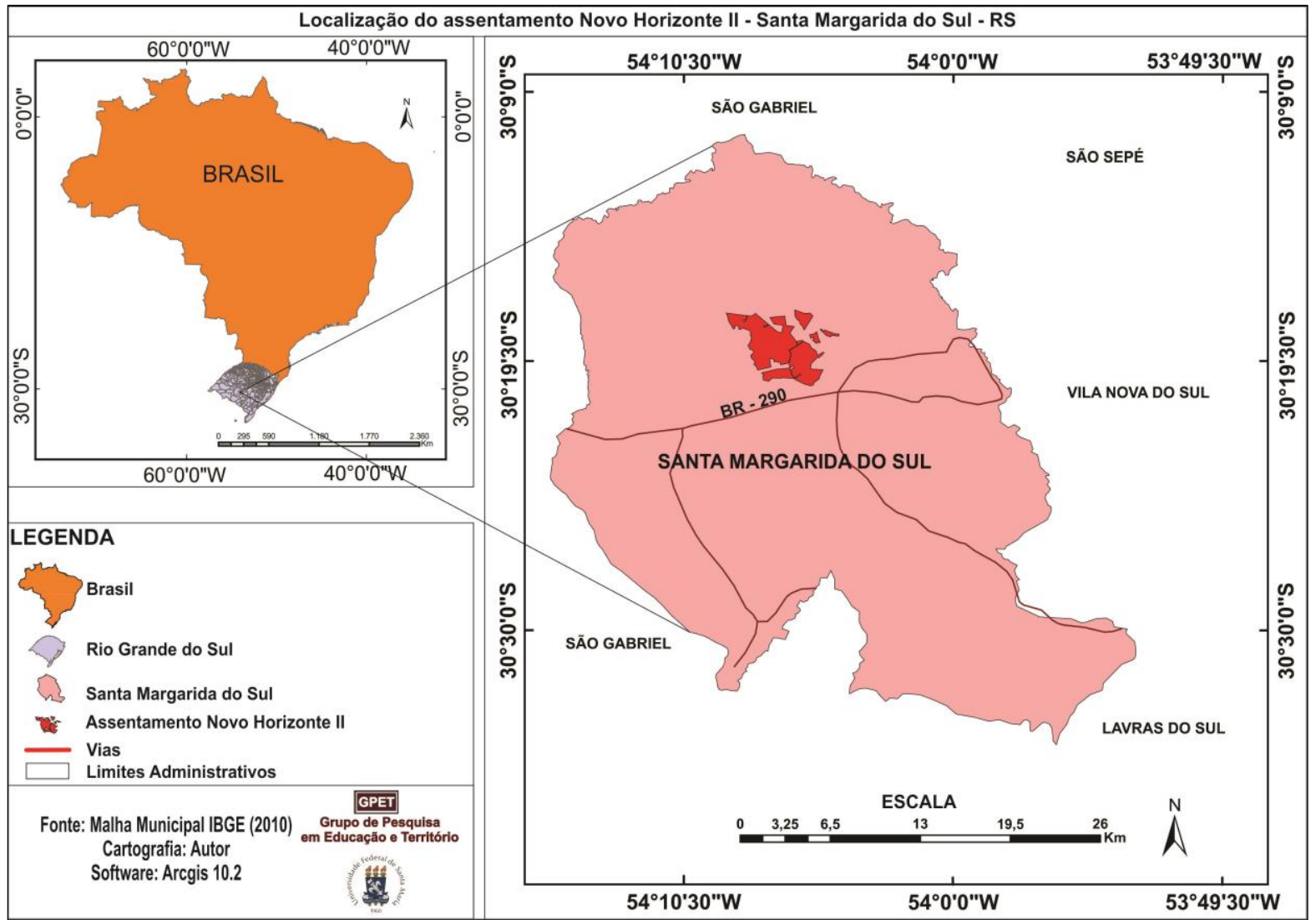

Fonte: Malha municipal 1:500000, IBGE (2010).

Organização: Autor

Segundo os dados da Prefeitura Municipal de Santa Margarida do Sul/RS, o município era distrito de São Gabriel/RS e foi emancipado em 1996, através da Lei no 10.751/96. O município tem em sua formação histórica, desde o tempo que fazia parte de São Gabriel/RS, a característica da monocultura agrícola e pecuária extensiva, que permaneceu com força por muito tempo, favorecendo os grandes latifúndios.

Os dados da Prefeitura Municipal confirmam que, até meados do século XX, a população se dedicava apenas a pecuária tradicional; com a construção da BR 290 nas décadas de 1960/1970, que corta o município, atraiu muitas pessoas de outras regiões do estado, que foram modificando a cultura da região, como é o caso da introdução da prática agrícola, que na atualidade é um setor forte da economia do município.

Este artigo tem como objetivo central compreender como se desenvolve a produção do arroz orgânico no assentamento Novo Horizonte II, localizado no município de Santa Margarida do Sul, compreendendo como essa estratégia interfere na organização do território.

Mais especificamente objetiva-se: identificar o sistema produtivo do arroz orgânico desenvolvido no assentamento em questão; compreender como a produção orgânica do arroz interfere no processo de territorialização; e apreender as transformações vividas pelos agricultores, com o início dessa nova forma de produção, nos aspectos sociais, econômicos e ambientais.

O presente artigo foi resultante de trabalho de campo no assentamento Novo Horizonte II, localizado no município de Santa Margarida do Sul. 
Para o desenvolvimento deste trabalho, foi utilizada uma abordagem qualitativa centrada no método dialético, que segundo Demo (2008, p. 99) "as contradições da própria realidade levam-na a transformar-se, em modos sucessivos de produção, algo como necessidade interna permanente".

A pesquisa também contou com apoio metodológico centrado na observação participante, entrevistas semiestruturadas e conversas informais que foram realizadas com os assentados do Novo Horizonte II, produtores de arroz orgânico e com os técnicos da Assessoria Técnica, Social e Ambiental à Reforma Agrária (ATES). Sendo que:

\begin{abstract}
A observação é uma técnica que sempre auxilia muito o pesquisador em suas pesquisas. A observação pode ser flexível e utilizada dentro de qualquer metodologia de pesquisa, tanto de abordagens quantitativas como qualitativas. Porém, o bom observador é aquele que, ao decidir-se pela observação, deverá preparar o seu desenvolvimento, o seu emprego e formas de registro [...] (BARROS; LEHFELD, 1990, p. 77).
\end{abstract}

Para usar as citações referidas ao trabalho de campo, usamos a letra A seguida do número da entrevista para representar a fala de assentados, e $\mathrm{T}$ seguida do número da entrevista para representar os técnicos.

O presente trabalho se constituiu em diversas etapas, onde na primeira etapa foi realizada uma caracterização geral da produção do arroz orgânico no assentamento em estudo, dando ênfase à base teórico-conceitual, trazendo reflexões de pensadores da questão agrária e a produção do arroz orgânico.

Em um segundo momento, o trabalho de campo no assentamento Novo Horizonte II. Neste momento, além de fazermos observações do local, também aplicamos entrevistas semiestruturadas. Nesta etapa, foram realizadas reflexões coletivas com a participação das famílias assentadas e de técnicos responsáveis pelo sistema produtivo, cujos temas centrais foram às transformações ocorridas neste espaço agrário, suas características, impactos do cultivo do arroz orgânico, bem como uma reflexão das transformações sociais, econômicas e ambientais ocorridas.

$\mathrm{Na}$ última etapa, sistematizamos os dados coletados, realizando interpretação e análise das informações para posterior geração de discussões e considerações referentes à pesquisa em questão.

\title{
2 Referencial teórico
}

A modernização do campo, que ocorreu através da Revolução Verde, a partir da década de 1960, foi responsável pelo aumento das desigualdades sociais, pois beneficiou os produtores de maior renda: os grandes produtores rurais, pelo fato de consumirem os pacotes tecnológicos disponibilizados no mercado, tais como: insumos químicos, agrotóxicos, maquinário e fertilizantes; os agricultores de baixa renda, que não tinham condições financeiras para adquirir as tecnologias oferecidas pelo mercado acabaram com dificuldades de reprodução social e econômica.

A produção de arroz no estado gaúcho se caracteriza pelo predomínio do uso intensivo de máquinas e insumos químicos durante todo o sistema produtivo. Desse modo, a orizicultura convencional é uma atividade econômica que gera cada vez menos empregos, produzindo crescentes impactos socioeconômicos e ambientais. 
Segundo Alencar; Menezes (2009), a modernização na agricultura impôs um enorme dano socioambiental, pela exploração inadequada dos recursos naturais, acarretando na erosão do solo, perda de fertilidade, sedimentação dos rios, entre outros.

\begin{abstract}
Nesse sentido, o modelo reprodutivo representado pela modernização agrícola pode ser contrastado com um diversificado elenco de estratégias e práticas sociais que tem entre seus objetivos o alargamento da autonomia técnica e produtiva e a obtenção de maior rendimento (...) (NORDER, 2004, p. 63).
\end{abstract}

Os assentamentos de reforma agrária priorizam cultivar alimentos diversificados, pois a produção familiar tem em sua essência a sustentabilidade e diversidade de produtos, na busca pela soberania alimentar, como é o caso da produção de arroz orgânico.

O processo de reforma agrária na referida área de estudo produziu novos territórios, lutas e conflitos, através da dominação, da apropriação e, por relações de poder que se fazem presentes, devido às tentativas sistemáticas de manutenção da grande propriedade, na maior parte das vezes improdutiva ou pouco produtiva.

Aliado ao processo de territorialização verifica-se também transformações na organização e reorganização do espaço, além da produção do arroz gerar modificações na paisagem do território.

[...] as sociedades, através de suas relações de trabalho, transformam a si e a natureza, resultando na produção do espaço que incorpora e reflete, na paisagem, a forma como diferentes grupos sociais se relacionam com a natureza. É todo espaço onde há possibilidade de vida e interação do homem. (Corrêa, 1995, p.22).

A opção pelo plantio de arroz orgânico no assentamento Novo Horizonte II é fruto de uma experiência exitosa realizada pela Cooperativa de Produção Agropecuária Nova Santa Rita (COOPAN), localizada no município de Nova Santa Rita/RS, onde os assentados estão transformando seus sistemas produtivos e trabalhando com formas de agricultura familiar sustentável, desenvolvendo um novo padrão de desenvolvimento rural.

Sendo que:

A ideia de assentamento está diretamente relacionada à de pequena produção. Lugar e relação social se processam enquanto fonte de poder e resistência; 'integrados' ou excluídos, os trabalhadores constroem, sempre, novas estratégias que garantam a manutenção de sua existência. Nesse sentido, a terra é também o espaço da luta, pois é onde se realizam os processos sociais. É nesse contexto que os espaços dos assentamentos e as diferentes dimensões das relações aí desenvolvidas pelos sujeitos emergentes nos interessam como processo socioespacial, em e onde se expressam as dimensões dos interesses da classe: como o acesso a terra, a organização do espaço econômico, cultural e político, pela reinserção no processo produtivo, participando da sociedade como cidadãos [...] (Fernandes, 1998, p.22).

Ao mesmo tempo em as famílias produtoras do arroz orgânico estão desenvolvendo um novo padrão de desenvolvimento, também estão resgatando a cidadania dos camponeses. Através de tais relações:

Os trabalhadores rurais persistirão na luta por novos padrões de desenvolvimento, no qual a reforma agrária continua sendo uma medida essencial para promover o desenvolvimento da agricultura e o resgate da cidadania para milhares de camponeses, que, expulsos da terra, se tornaram excluídos do processo produtivo e 
dos centros de decisão. A reforma agrária e a formação dos assentamentos rurais constituem instrumentos estratégicos para o fortalecimento, a expansão e a consolidação do modelo familiar de agricultura. (Sauer, 1998, p.17).

Cada assentamento desenvolve os sistemas produtivos levando em conta suas peculiaridades, visualizadas na forma que as famílias configuram seu espaço, organizando e reorganizando o espaço dentro do assentamento. As famílias transformam as características físicas do espaço, modificando a paisagem, inserindo no espaço local, novas formas de produção, sistemas produtivos diferentes do convencional, sendo este, pensado a partir do coletivo, dando dessa forma, características produtivas próprias para cada assentamento.

O cultivo do arroz orgânico produzido nos moldes agroecológicos faz com que os assentados busquem sistemas e técnicas produtivas para que realmente se produza um produto saudável e de qualidade, desenvolvido para satisfazer as novas demandas de consumidores que priorizam a compra de alimentos saudáveis, além de que, a produção orgânica leva em conta as questões sociais, econômicas e ambientais, fazendo com que se alcance o desenvolvimento rural sustentável dentro dos assentamentos.

\footnotetext{
Enquanto a corrente agroecológica defende uma agricultura de base ecológica que se justifique pelos seus méritos intrínsecos ao incorporar sempre a ideia de justiça social e proteção ambiental, independentemente do rótulo comercial do produto que gera ou do nicho de mercado que venha a conquistar, outras propõem uma "agricultura ecologizada", que se orienta exclusivamente pelo mercado e pela expectativa de um premio econômico que possa ser alcançado num determinado período histórico, o que não garante sua sustentabilidade no médio e longo prazos. (Caporal; Costabeber, 2002, p. 81)
}

Caporal; Costabeber (2002) ainda ressaltam que, uma agricultura verdadeiramente de base ecológica não pode se restringir apenas a preocupação ambiental, sendo fundamental incorporar outras dimensões, como a social, a econômica, a cultural, a política e a ética.

A partir do desenvolvimento das práticas agrícolas nos moldes agroecológicos, os assentados passam a preservar os recursos naturais, além da cultura e biodiversidade local, permanecem no campo garantindo a produção para o sustento familiar e a venda de excedentes, e assim, garantindo sua reprodução social.

\section{Resultados e discussões}

O assentamento Novo Horizonte II teve sua história de organização com lutas permanentes e acampamentos. Segundo o entrevistado T-01 (2013), a formação dos acampamentos na região se deu no ano de 2003. Os anos que as famílias ficaram nos acampamentos variaram de três a nove anos, sendo este período de luta permanente. As famílias são oriundas, principalmente, da região norte e metropolitana do Rio Grande do Sul, mas também há famílias da região da fronteira oeste do RS.

Segundo o entrevistado T-01 (2013), as famílias começaram a chegar ao assentamento em 2008, onde eram 86 famílias, oriundas de diversas regiões do estado. A metodologia escolhida para dividir as famílias nos lotes e, posteriormente à divisão das famílias em grupos de produção foi de acordo com as afinidades produtivas. 
Várias famílias do assentamento Novo Horizonte II integraram o Movimentos dos Pequenos Agricultores (MPA), e fizeram a luta em conjunto com o MST. Estes assentados têm a característica de que, grande parte são filhos de agricultores familiares, e alguns, de camponeses assentados, assim, já têm experiências com a produção agrícola, facilitando na organização e no desenvolvimento dos sistemas produtivos.

Segundo o entrevistado A-01 (2013), os filhos de camponeses trabalham de forma séria na lavoura, pois se programam diariamente para as atividades agrícolas, e têm consciência que os lucros de suas atividades variam de acordo com o período da safra, e que, "muitos assentados do espaço urbano conseguem produzir e ficar no lote, os que realmente não se adaptam acabam por ir embora".

O entrevistado T-02 (2013), destaca que o assentamento possui uma área total de 1.650 hectares, que estão divididos em 86 lotes. $\mathrm{O}$ arroz orgânico começou a ser produzido no assentamento em 2009, atualmente, um grupo composto de seis famílias trabalham com este sistema produtivo.

A expansão da cadeia produtiva do arroz orgânico se dá pelo fato de ter menor custo que a produção se comparado ao arroz convencional, porém, é necessária dedicação diária com relação ao manejo do solo, armazenagem e germinação das sementes, produção de biofertilizantes, controle das pragas e do volume de água na lavoura, ou seja, durante todo o sistema produtivo o assentado participa sistematicamente.

Segundo o entrevistado T-01 (2013), os assentados que começaram a produzir de forma convencional acabaram não obtendo sucesso, pois sua renda será menor devido aos altos custos produtivos.

Desde que os assentados vieram para o assentamento, já começaram a discutir a produção do arroz na forma orgânica, produzindo assim, um alimento de qualidade, dando uma resposta positiva para a sociedade, comprovando que a reforma agrária realmente dá certo.

O entrevistado A-01 (2013) cita que no assentamento só se produz arroz na forma orgânica, sendo que, na última safra, foram cultivados em torno de 41 hectares, onde toda a produção foi destinada para a Cooperativa dos Trabalhadores Assentados da Região de Porto Alegre (COOTAP). Nas imagens 1, 2, 3 e 4 da Figura 2 podemos visualizar a lavoura de arroz orgânico do assentamento. 
Figura 2: Lavoura de arroz orgânico do assentamento Novo Horizonte II.

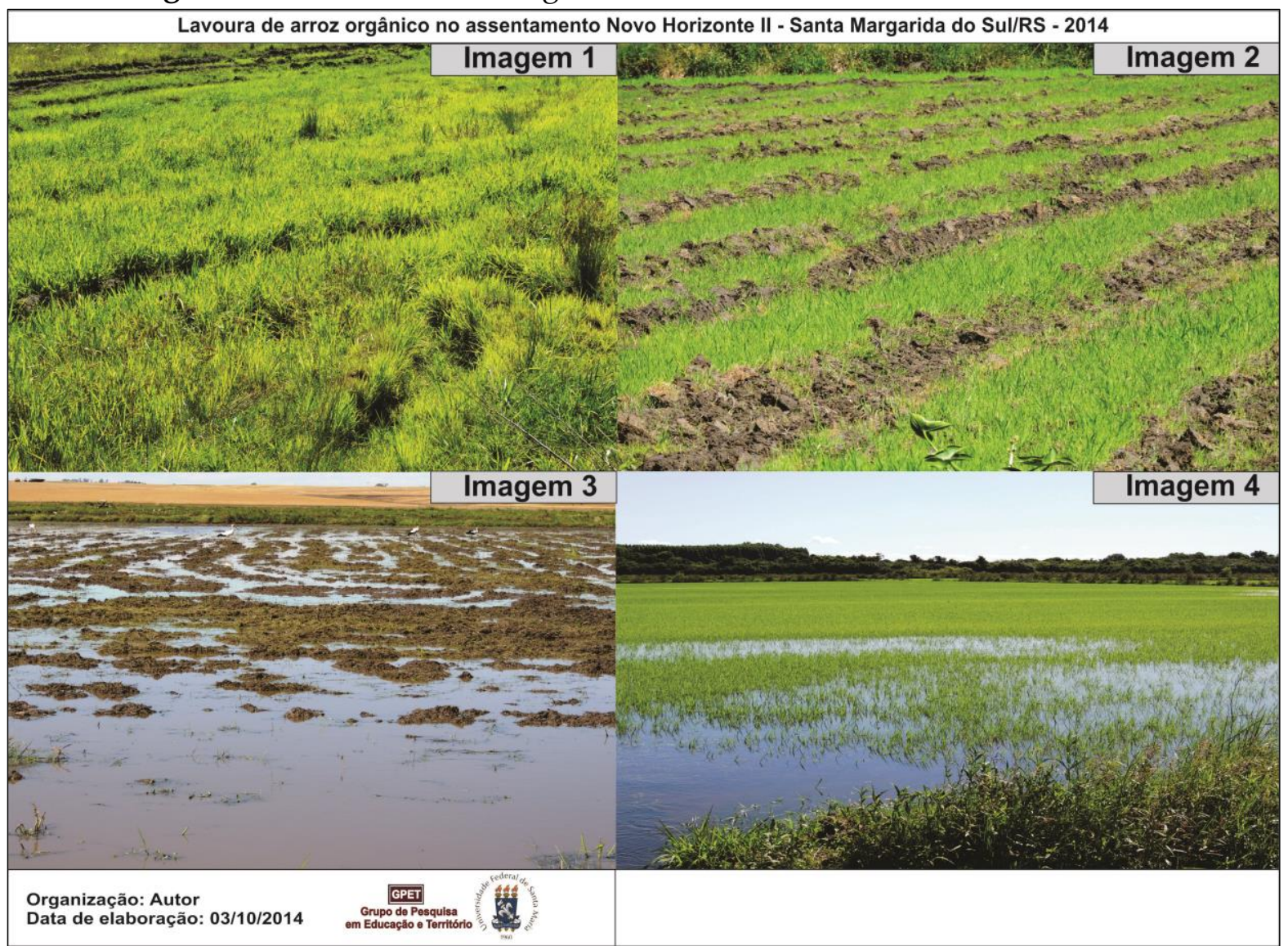

Fonte: Trabalho de campo

Organização: Autor

No assentamento em questão, além da linha de produção do arroz orgânico, também é produzido leite e hortifrutigranjeiros nos moldes agroecológicos, assim; os recursos financeiros se destinam para as três linhas de produção, investindo em materiais específicos, visando atender as necessidades prioritárias de cada uma das linhas produtivas.

O entrevistado T-01 (2013), salienta que a área da propriedade deveria seguir os moldes do módulo rural regional, correspondente a 24 hectares. O grande desafio corresponde ao agricultor assentado possuir metade do lote na área de várzea e a outra metade na área seca, pois assim, os assentados conseguiriam plantar o arroz orgânico e também continuar produzindo leite e hortifrutigranjeiros, o que tornaria o lote sustentável.

A produção do arroz orgânico garante retorno econômico elevado para as famílias produtoras, devido aos custos produtivos serem bem menores do que a do arroz convencional, pois nesse sistema produtivo não há uma dependência com os insumos externos e nem de grande quantidade de maquinário moderno.

Neste sentido, ao participarem dos processos que envolvem a organização produtiva do arroz orgânico, as famílias assentadas rompem, não apenas com um padrão de produção agrícola dependente de insumos externos, mas constroem novas relações socioespaciais, engendrando significativas transformações territoriais e ambientais no assentamento.

A produção orgânica do arroz está aumentando com as políticas de fortalecimento da agricultura familiar camponesa, a exemplo do Programa de Aquisição de Alimentos 
(PAA), Programa Nacional de Alimentação Escolar (PNAE) e Programa Nacional de Fortalecimento da Agricultura Familiar (PRONAF).

Para que a produção de arroz na forma orgânica se torne viável, é de extrema importância o apoio técnico e financeiro, como é o caso da ATES e da COOTAP, que garantem de forma direta e indireta o aumento da produção do arroz orgânico no assentamento em estudo, associado ao aumento da qualidade e a quantidade produtiva.

A assistência técnica no assentamento Novo Horizonte II é de responsabilidade da ATES. Para desenvolver a produção do arroz orgânico, os agricultores trabalham com as técnicas que conhecem, e a ATES faz as orientações durante todo o desenvolvimento dos sistemas produtivos, com visitas as lavouras e aos produtores, para aplicações de técnicas e tecnologias que garantam o desenvolvimento dos sistemas produtivos de forma eficiente. É importante ressaltar que a agroecologia é um dos princípios da ATES.

Segundo o entrevistado A-01 (2013), que foi o pioneiro na produção de arroz orgânico na região, no início da produção houve muitas críticas, pois os demais agricultores pensavam que essa forma de produção não era viável.

\begin{abstract}
Os assentados, no início, não sabiam direito como produzir o orgânico, sendo um desafio para os técnicos agrícolas se capacitarem para dar uma resposta positiva aos produtores de arroz, pois os produtores tinham uma grande deficiência técnica logo no início da produção no assentamento, sendo que o técnico da época fez um esforço enorme para se capacitar e auxiliar os produtores neste processo produtivo. (A-01, 2013).
\end{abstract}

Conforme o entrevistado A-01 (2013) “[...] é um desafio desenvolver a produção no modelo orgânico", pois o desenvolvimento desta produção é lenta e ganha forças na troca experiências, nos dias de campo com outros produtores, com a assistência técnica de qualidade, que é de extrema importância para o melhoramento qualitativo da produção, onde; com a troca de saberes se adquire conhecimento das melhores formas de trabalhar com o cultivo do arroz orgânico.

O assentamento Novo Horizonte II trabalha nos moldes da agricultura biodinâmica, desenvolvendo técnicas e tecnologias que se adaptem a cada lavoura e consequentemente, um aumento na produção e na produtividade.

\footnotetext{
A técnica mais utilizada na melhora da fertilidade do solo para a produção de arroz orgânico no assentamento é o pó de rocha, tal auxilia diretamente na melhora qualitativa do solo. Utiliza-se a rocha cristal que é ácida, sendo que tal técnica está respondendo diretamente no aumento da produtividade, pois melhora substancialmente a qualidade dos solos. (T-01, 2013).
}

Na Figura 3 podemos observar a matéria prima para o preparo biodinâmico composto por pó de rocha, que será usado como adubo orgânico na lavoura do assentamento. 
Figura 3: Pó de rocha.

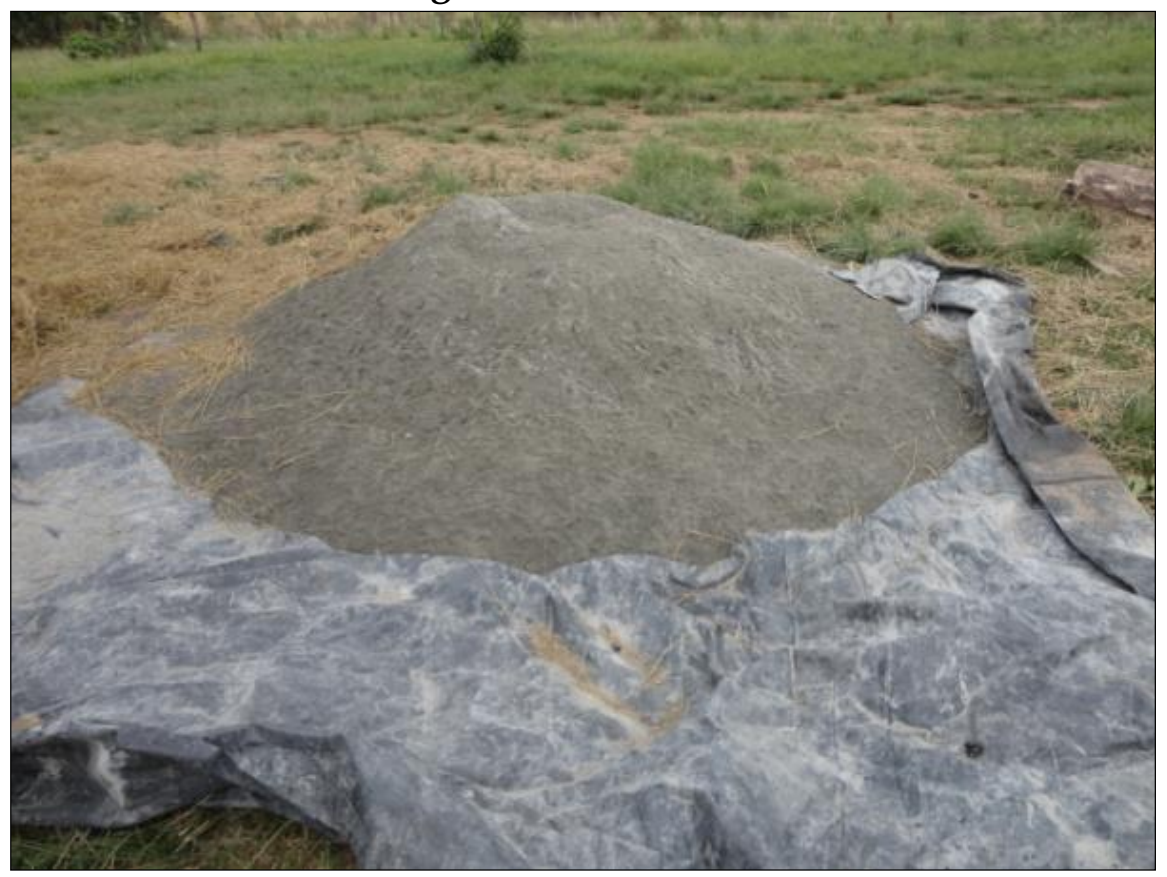

Fonte: Trabalho de campo

Organização: Autor

O entrevistado A-01 (2013), relata que os assentados produzem oito variedades de arroz orgânico, com destaque para a produção do arroz cateto, agulha, preto, três variedades japonesas e duas variedades aromáticas, todas possuem ótima aceitação no mercado. A produtividade varia de acordo com cada variedade. Conforme o entrevistado “O arroz agulha possui comércio garantido, sendo que os produtores agregam $20 \%$ do valor no arroz, por se um produto orgânico".

Neste assentamento, também é realizado o resgate e multiplicação de cultivares crioulas. Segundo o entrevistado T-01 (2013), "muitas sementes, por estarem a muito tempo esquecidas, devem ser resgatas, desenvolvendo técnicas de produção apropriadas para cada variedade, para que as mesmas não se eliminem".

As cultivares crioulas, pelo fator de se ter poucas sementes, passam por algumas técnicas especiais de plantio, como é caso da confecção de mudas, para somente depois transplantá-las, garantindo que as mesmas produzam com qualidade.

$\mathrm{Na}$ propriedade que visitamos durante o trabalho de campo, há estoque de cultivares crioulas, com variedades de valor significativo, estas cultivares crioulas de arroz, possuem um alto valor no mercado, partindo disso, muitos assentados acabam produzindo tais variedades para um determinado nicho de mercado. Na figura 4 podemos ver sacas de semente de arroz de diversas variedades estocadas no assentamento. 
Figura 4: Estoque de cultivares crioulas de arroz.

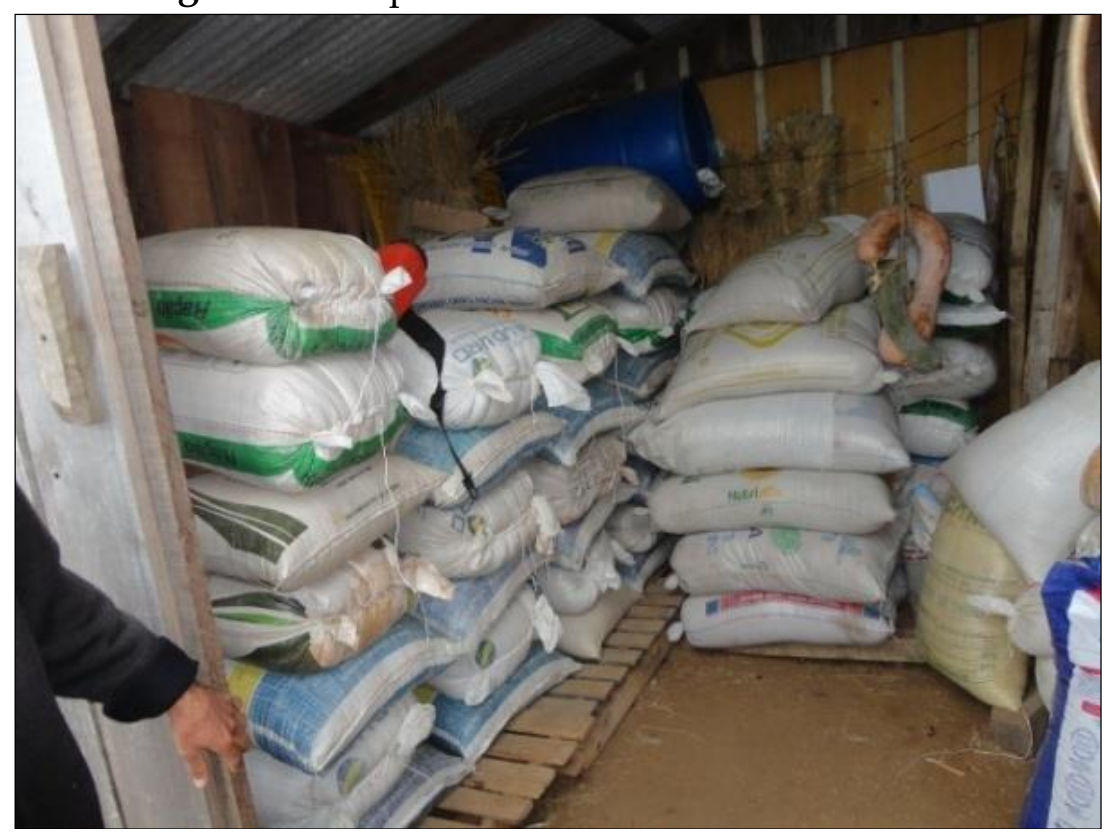

Fonte: Trabalho de Campo

Organização: Autor

Conforme os entrevistados A-01; T-01 (2013), o maior problema enfrentado pelos assentados está relacionado à questão estrutural, não somente aos aspectos relacionados à produção, mas de infraestrutura de casas, estradas, água, luz, entre outros; que acabam afetando, além da agricultura, toda a estrutura familiar. Deve-se ainda, ter uma boa infraestrutura de transportes e armazenamento da produção, para facilitar a colheita e retirada da produção da lavoura, pois se esta não for facilitada, a cadeia de produção não irá se processar com sucesso.

O maior desafio da produção orgânica está relacionado à estruturação das famílias, através da cooperação e do domínio das tecnologias produtivas, melhorando as técnicas de manejo para posteriormente dominar todas as etapas produtivas da cadeia.

\section{Considerações finais}

A produção orgânica é uma forma de se opor ao sistema convencional, melhorando de forma quali-quantitativa a vida dos agricultores assentados.

A transição da agricultura convencional para a orgânica é uma mudança que visa não utilizar mais insumos químicos durante o processo produtivo, se utiliza de métodos, metodologias, tecnologias e princípios que respeitem os recursos naturais e a sociedade. Sendo esta uma evolução contínua, que está sempre na busca de técnicas e tecnologias que melhor se adaptem a realidade local e que facilitem a produção dos produtos orgânicos.

A importância da diversificação da produção dentro do lote garante renda mensal aos assentados, visto que o arroz orgânico traz renda anual. A produção de alimentos para o consumo familiar e a venda de excedentes garante a autonomia produtiva das famílias na busca pela soberania alimentar.

$\mathrm{Na}$ atualidade, a sociedade está visualizando que é necessário criar novas formas produtivas, que sejam realmente sustentáveis, com aceitação nos mercados e feiras de 
produtos orgânicos e, por esta aceitação ser positiva, a produção orgânica está aos poucos conquistando os consumidores.

Também é de Horizonte II, as cooperativas, a assistência técnica e a troca de saberes e experiências entre os agricultores, pois além de viabilizar as condições produtivas, também favorecem a expansão da área plantada e do número de famílias envolvidas com a produção do arroz orgânico.

A produção do arroz orgânico tem custos bem menores do que a produção do arroz convencional, o que garante para as famílias um rendimento econômico elevado. Quando se compara os custos de produção, é mais compensatória a cultura orgânica, mesmo que produza menos, os preços para a comercialização são superiores, isso gera maior rendimento econômico para as famílias.

A produção de arroz orgânico no assentamento Novo Horizonte II potencializa o desenvolvimento local e regional, pois é uma cultura sustentável de forma socioambiental e economicamente, sendo muito viável ao agricultor camponês assentado.

\section{REFERÊNCIAS}

ALENCAR, M. T. de; MENEZES, A. V. C. de. Ação do Estado na produção do espaço rural: Transformações territoriais. In: CAMPO-TERRITÓRIO: revista de geografia agrária, v.3, n.5, p.113-133, fev. 2009. Disponível em: <http://www.campoterritorio.ig.ufu.br/>. Acesso em: 24 fev. 2013.

BARROS, A. de J. P. de; LEHFELD, N. A. de S. Projeto de pesquisa: propostas metodológicas. Petrópolis, RJ: Vozes, 1990.

BRUNO, R. Agronegócio e novos modos de conflituosidade. In: FRENANDES, B. M. (org.). Campesinato e agronegócio na América Latina: a questão agrária atual. São Paulo: Expressão Popular, 2008.

CAPORAL, F. R. COSTABEBER, J. A. Análise multidimensional da sustentabilidade: uma proposta metodológica a partir da Agroecologia. Agroecologia e Desenvolvimento Rural Sustentável, v.3, n.3, p.70-85, jul./set. 2002 b.

CHAYANOV. A. Sobre a teoria dos sistemas econômicos não capitalistas. In: SILVA, J. G. da; STOLCKE, V. (org.). A questão agrária. São Paulo: Brasiliense, 1981, p. 133-164.

CORRÊA, R. L. Espaço: um conceito chave em geografia. In: CASTRO, I. E. de; GOMES, P. C. da C.; CORREAA, R. L. Geografia: conceitos e temas. Rio de Janeiro: Bertrand Brasil, 1995.

DAVID, C. de. Agricultura familiar em assentamentos rurais: contribuições à dinâmica regional do sul do estado do Rio Grande do Sul. In: MARAFON, G. J.; PESSÔA, V. L. S. (Org.). Agricultura, desenvolvimento e transformações socioespaciais: reflexões interinstitucionais e constituição de grupos de pesquisa no rural e no urbano. Uberlândia/MG: Assis Editora, 2008. p.15 - 38.

DEMO, P. Metodologia do Conhecimento Científico. São Paulo: Atlas, 2008. 
EMBRAPA. Embrapa Agrobiologia. Fundamentos da agricultura orgânica. Sistemas de Produção, 2 - 2ª Edição. ISSN 1806-2830. Versão Eletrônica. Dez. 2006. Disponível em: http://sistemasdeproducao.cnptia.embrapa.br/FontesHTML/Cafe/CafeOrganico_2ed/funda mentos.htm>. Acesso em: 07 de jul. 2013.

FERNANDES, B. M. Questões teórico-metodológicas da pesquisa geográfica em assentamentos de reforma agrária. Núcleo de Estudos, Pesquisas e Projetos de Reforma Agrária. Presidente Prudente: UNESP, 1998.

IBGE. INSTITUTO BRASILEIRO DE GEOGRAFIA E ESTATÍSTICA. CIDADES@. Disponível em: $<$ http://www.cidades.ibge.gov.br/xtras/perfil.php?lang=\&codmun=431697\&search=riogrande-do-sul I santa-margarida-do-sul >. Acesso em: 01 mai. 2014.

NORDER, L. A. C. Mercantilização da agricultura e desenvolvimento territorial. 2004. In: SCHNEIDER, Sérgio. A Diversidade da Agricultura Familiar. Porto Alegre: Ed. UFRGS, 2009.

PREFEITURA MUNICIPAL SANTA MARGARIDA DO SUL. A CIDADE. Disponível em: $<$ http://www.santamargaridadosul.com/new/?lk=cidade>. Acesso em: 01 mai. 2014.

SAUER, S. Reforma agrária e geração de emprego e renda no meio rural. São Paulo: ABET, 1998. 